\title{
ALAIN ROBBE-GRILLET Y SU CRECIENTE PARODIZACIÓN DEL GÉNERO POLICIAL
}

The growing parody of detective fiction by Alain Robbe-Grillet

Clemens August Franken Kurzen*

Resumen

Luego de entregar algunos breves antecedentes biobibliográficos del autor francés Alain Robbe-Grillet, se analiza con profundidad los principios esenciales de la poética de la "Nueva Novela" francesa, ante todo las rupturas del tiempo y espacio convencional, para estudiar su presencia en sus primeras dos novelas, Las gomas y El mirón, que llevan aún ciertos rasgos policiales. Este análisis literario revela su carácter híbrido y posmoderno y una creciente parodización del género policial.

Palabras clave: Alain Robbe-Grillet, Nouveau Roman, novelas policiales, parodia.

Abstract

The paper provides a brief bio-bibliographical background of the French author Alain Robbe-Grillet and analyses in depth the basic principles of the 'New French Novel'. It accounts for its conventional time and space breach and looks into its presence in his first two novels; The erasers and Jealousy, which still bear some traces of the detective fiction. This literary analysis exposes their hybrid and postmodern character and the growing parody being made of the police genre.

Key words: Alain Robbe-Grillet, Nouveau Roman, detective fiction, parody.

\section{ANTECEDENTES BIOBIBLIOGRÁFICOS}

El escritor y cineasta francés Alain Robbe-Grillet nació en Brest en 1922 y murió en 2008. Estudió Agronomía en Paris y trabajó en el Instituto Nacional de Estadística y en un centro de investigación de frutas tropicales. Su profesión que abandonará pronto por la escritura lo llevó a viajar por África y las Antillas. En 1953 y 1955 publicó sus primeras novelas Las gomas (Les gommes) y El mirón (Le voyeur) que lo convierten en un “"verdadero' creador de novelas policiales" (Janvier, 1967, p. 33). Tanto estas primeras dos "antinovelas" (Sartre), en las que se centrará este análisis, como las posteriores novelas La celosía (1957), En el laberinto (1959), La inmortal (1963), La

\footnotetext{
1 'Wahren' Schöpfer von Kriminalromanen. Según Michael Holquist, “[t] hus, when after World War II RobbeGrillet was searching for ways to overcome the literary tradition of the novel he so naturally turned to the detective story as a mode...." (citado en Cawelti, 1976, p. 137) ("[a]sí, cuando Robbe-Grillet después de la Segunda Guerra Mundial buscaba caminos para romper con la tradición de la novela se inclinó naturalmente al relato policial como una manera...").
} 
casa de citas (1965), etcétera, se caracterizan por una búsqueda intensa, un preguntar insistente y la intención de desvelar y desenmascarar un misterio (Janvier, 1967, p. 42), es decir, "todos los libros [...] de Alain Robbe-Grillet son novelas policiales, por más que resulten dificiles de leer en cuanto tales" (Albéres, 1971, p. 165). Famoso es también su escrito teórico más importante "Por una nueva novela" (Robbe-Grillet, 1964) que lo "convirtió en el principal portavoz del "Nouveau Roman"” (Guerrero, 1996, p. 5). Menos éxito tuvo Robbe-Grillet como miembro de la "escuela de la mirada" cuando en 1961 dio el "paso definitivo hacia el cine, con su guión para la película de Resnais ‘El año pasado en Marienbad'. En 1963 escribirá el guión de su propia cinta,

“"La inmortal', [...] La ambiciosa obra fue mal recibida por los cineastas de la 'Nueva ola"' (Guerrero, 1996, p. 8). La recepción de la corriente literaria del Nouvau Roman, a la que pertenecen, aparte de Alain Robbe-Grillet, Michel Butor, Claude Simon, Nathalie Sarraute, Robert Pinget, Claude Ollier y Marguerite Duras, es bastante ambigua; hay defensores de la talla del famoso crítico literario francés Roland Barthes y detractores de la importancia de un Ernesto Sábato que ya en 1972 le reprocha indignado que "como invariablemente ocurre con los movimientos refinados y bizantinos, no produjo ningún gran escritor ${ }^{3}$. [...] Lamentablemente, a su [Robbe-Grillet; C. F.] literatura acompaña una doctrina totalitaria y hasta terrorista, que pretende convertir a los demás narradores en una fauna aberrante y desamparada" (Sábato, 1972, p. 11-12). Vemos ahora más en detalle lo que caracteriza dicha corriente literaria francesa.

\section{POÉTICA DE ROBBE-GRILLET Y DEL NOUVEAU ROMAN}

Siguiendo en adelante a Patricia Martínez (1987), Alain Robbe-Grillet pertenece a una generación de escritores franceses que asume la práctica de la escritura como necesaria ruptura con los presupuestos formales, representativos e ideológicos de la novela tradicional y como una búsqueda y experimentación de nuevas fórmulas narrativas. El Nouveau Roman, sin embargo, no es un fenómeno aislado, sino se enmarca en un amplio proyecto de ruptura y renovación que intentará despojar a la literatura de las grandes palabras y de las bellas formas y nociones. Sus precursores son, en primer lugar, G. Flaubert, quien concede prioridad absoluta a la

\footnotetext{
${ }^{2}$ Esta denominación aparece por primera vez en 1958 en la revista Esprit que le dedicó un número entero. Según Linda Unmüssig (1997), detrás de los esfuerzos teóricos de Robbe-Grillet está menos "una desinteresada búsqueda de verdades abstractas" ("eine desinteressierte Suche nach abstrakten Wahrheiten") que "la percepción de lo que es posible y lo más productivo para ese nuevo tipo de ficción” (die Wahrnehmung dessen, was möglich und was am produktivsten ist für die neue Art der Fiktion) tomando en cuenta que las obras tempranas del nouveau roman fueron fuertemente criticadas tanto por parte "del establisment literario conservador" (vom konservativen literarischen Establishment) como por parte "de los comunistas e izquierdistas en tomo a Sartre" (den Kommunisten und der Linken um Sartre) (p. 43-44).

${ }^{3} \mathrm{Si}$ se incluyese a Samuel Beckett en esta corriente literaria, como algunos lo hacen, el juicio de Sábato sería erróneo.
} 
dimensión formal de la novela en detrimento del contenido, y cuyo sueño siempre fue el de escribir "un libro sobre nada" en el que se pusiese de manifiesto la autosuficiencia del propio lenguaje y el carácter significativo de la forma. En segundo lugar, M. Proust, quien introduce innovaciones estructurales en su obra principal, niega el orden cronológico clásico, elimina a menudo la intriga novelesca, convirtiendo su escritura en una búsqueda y experimentación de nuevas tácticas expresivas. Luego F. Kafka quien supera definitivamente el relato realista y escribe obras abiertas que subvierten el orden lógico, rompiendo de esta forma con el pacto de certidumbre entre lector y autor. También Dennis Porter (1981) destaca, ante todo, la importancia de la metáfora kafkiana del mundo como laberinto como decisiva "para la experiencia humana entre autores posmodernos como Borges y Robbe-Grillet" y alude especialmente a la novela El proceso, en la que "Kafka proyecta la visión fantasmagórica de una ley misma como un laberinto que debe ser resuelto" (p. 251-52). En cuarto lugar J. Joyce, cuyo Ulysses es un paradigma de la más absoluta ruptura con los presupuestos formales de la novela tradicional. Finalmente W. Faulkner con su peculiar sentido de la ficción, el distanciamiento del yo narrador, su omnisciencia siempre cuestionada, la continua omisión de acontecimientos y el desorden cronológico.

Detrás de todas estas rupturas e innovaciones está, según Patricia Martínez (1987), el hecho más bien metafísico y cultural que el discurso occidental tradicional, basado en el orden de la razón, empezó a tambalearse a partir de la ruptura epistemológica realizada por Nietzsche y que las dos guerras mundiales significaron un gigantesco fracaso histórico de este discurso lógico, provocando un sentimiento general del absurdo existencial. Pero mientras Sartre y Camus tratan de racionalizar el absurdo, elaborando un humanismo existencialista y una literatura comprometida con él, los representantes de la "Nueva Novela" le oponen su "antihumanismo" estructuralista". Para ellos la literatura y la novela no están al servicio de unos fines morales, sentimentales o ideológicos; escribir no es probar ni seducir, ni siquiera inquietar o despojar al lector de todas las ilusiones para hacerlo tomar conciencia de las injusticias de la sociedad, de las falacias de la civilización o del absurdo de la

\footnotetext{
${ }^{4}$ For human experience among such postmodernists as Borges and Robbe-Grillet. Kafka projects the nightmare of the law itself as a labyrinth to be solved.

${ }^{5}$ Según Kurt Wilhelm (1969), Robbe-Grillet no elimina al hombre como muchos críticos sostienen, sino le sigue otorgando el primer lugar en el mundo. Sin embargo, al mismo tiempo, ya no considera al hombre como el sentido último del mundo. "Su interés principal no se centra en las cosas, sino en el hombre y su posición en el mundo. El ser humano está en todas partes presente en sus novelas. En ellas hay muchas cosas, 'cosas' o más general: 'objetos', pero siempre primero una mirada humana que los percibe" (Sein Hauptinteresse gilt nicht den Dingen, sondern dem Menschen und dessen Stellung in der Welt. Der Mensch ist überall anwesend in seinen Romanen. Es gibt darin viele Dinge, 'choses' oder allgemeiner: 'objets', immer aber zuerst einen menschlichen Blick, der sie wahrnimmt) (p. 18). Julian Symons (1992) confirma esta interpretación de Wilhelm al decir en relación con la novela "Las gomas" que "seguramente tiene un detective, Wallas, quien es el centro de la acción en el sentido de que todo es visto por sus ojos, [...]" (certainly contains a detective, Wallas, who is at the centre of the action in the sense that everything is seen through his eyes, [...] (p. 221)).
} 
condición humana. Tampoco les interesa decir verdades, porque no creen en ellas, sino las formas del decir. Solo les interesan las preguntas. "Misterios son más bien creados que resueltos"6 (Cawelti, 1976, p. 137). Por eso renuncian a todo significado y a toda referencia fuera de la literatura misma. Como dice Robbe-Grillet en su ya mencionado ensayo "Para un nueva novela", "[e]l mundo no es significante ni absurdo. Simplemente es". Comentando dicha afirmación, Kurt Wilhelm (1969) expone y precisa lo siguiente:

Entre hombre y cosa no hay una alianza del alma, ni solidaridad, ni unidad, ni orden preestablecido y, por eso, no se puede establecer ninguna analogía entre los dos. El mundo de las cosas sin ninguna relación íntima con la psique no puede ser expresión metafórica de sensaciones psíquicas ni imagen de la vida psíquica del hombre ${ }^{7}$ (p. 16).

Estamos, por tanto, ante una literatura amimética y radicalmente antirrepresentativa que rompe con la larga tradición literaria de la escritura "realista" con su discurso reproductor de sentido. Robbe-Grillet pretende solamente crear nuevas realidades verbales, recorriendo la superficie de los objetos, respetando su incertidumbre, su inconsistencia metafísica o su angustiosa contundencia (ver Patricia Martínez, 1987, p. 9ss). Esto vale especialmente para su segunda fase creativa del así llamado Nouveau Roman ${ }^{8}$ donde evita cualquier antropomorfismo, mensaje o caracterización de un héroe, escribiendo así antinovelas "absolutamente subjetivas" (Wilhelm, 1969, p. 18), es decir, obras artísticas autónomas que no buscan investigar la realidad sino a sí mismas. De esta forma, según R. M. Albéres (1971), la trama de la novela ya no es "una historia, una aventura o un destino de una persona determinada en un mundo siempre determinado, sino la novela consiste hoy de una cierta secuencia de determinados sucesos que pueden ser difíciles de interpretar. Mundo y héroe son indefinidos" (p. 176). Robbe-Grillet reconoce que un tiempo pensó que estaba interesada en la descripción exacta de la realidad, sin embargo, durante la redacción de El mirón se dio cuenta de que todo era solamente una ilusión realista, una pura construcción literaria, y que "la realidad empírica de los por él tan minuciosamente 'descritas' gaviotas le era totalmente indiferente" (Butters, 1977, p. 81).

Debido a que la materia que propone la nueva novela no es ordenada, provocando en el lector la misma sensación de extrañeza ontológica que experimenta el escritor y el hombre en general frente al mundo, al lector le corresponde estructurar la materia y darle un sentido. Según Francoise van Rossum-Guyon, "[e]1

\footnotetext{
${ }^{6}$ Mysteries are created rather than solved in their works.

${ }^{7}$ Zwischen Mensch und Ding besteht kein Seelenbündnis, keine Solidarität, keine Einheit, keine prästabilierte Ordnung, und daher können keinerlei Analogien zwischen beiden aufgestellt werden. Die Dingwelt, ohne innige Beziehung zur Psyche, kann nicht metaphorischer Ausdruck für seelische Empfindungen, Gleichnis für das Gefühlsleben des Menschen sein.

${ }^{8}$ Ver Leo Pollmann quien distingue dos épocas, el Nouveaus Roman clásico (1948-1956/57) y el Nouveau Roman puro (1957-1959) (citado en Martínez, 15).

${ }^{9}$ Die empirische Wirklichkeit der von ihm so minutiös 'beschriebenen' Möven ihm völlig gleichgültig war" 
lector no solamente colabora con los textos, sino también aporta que logren constituirse, ya que es él quien los hace funcionar finalmente"10 (p. 157). Una nueva forma de escribir exige por tanto una nueva forma de leer. Por eso, Francoise van Rossum-Guyon rechaza a críticos literarios que en una novela sin personas e intrigas buscan desesperadamente de identificar personas y reconstruir intrigas. Consecuentemente, Robbe-Grillet le pide en 1963 que el lector "1" "participara en una creación, que por su parte inventara la obra -y el mundo-", convirtiéndose, así, en "un partner autónomo" (Lange, 1971, p. 392).

De esta forma la novela nueva se independiza del autor y creador, formando un sistema cerrado y autosuficiente, un cosmos sin implicaciones personales, afectivas o históricas. Consecuentemente, los teóricos literarios del estructuralismo francés declararon la muerte del hablante individualizado y de la conciencia individual que se difumina frente "al sistema como totalidad" (ver Ricoeur).

Dos consecuencias inmediatas son, según Patricia Martínez, la novela antihumanista y la novela formalista. La última se caracteriza, en primer lugar, por la desaparición del personaje y de la psicología individual como centro organizador de la ficción, la supresión de la lógica de las acciones como factor de estructuración del relato. En vez de héroes hay seres anónimos, neutros, indefinidos, de oscuras motivaciones y obsesiones fútiles. Tampoco hay un punto de vista único que es desplazado por una multiplicidad de perspectivas. En segundo lugar, el desorden cronológico se convierte en un rasgo estructural característico de la novela formalista, con el consecuente aniquilamiento de la anécdota. A la progresión convencional de la trama de la novela se sustituye la yuxtaposición de secuencias inconexas, se subvierte la ordenación lineal del tiempo y a menudo se aproxima al grado cero de narratividad. En tercer lugar, hay un hiperdesarrollo de la coordenada espacial, es decir, una novela formalista esencialmente descriptiva en la que lugares y objetos cobran una inusitada relevancia mientras que personajes y acciones son relegados a un plano meramente tangencial. En cuarto lugar, hay una atención especial a la dimensión técnica de la novela: por ejemplo, procedimientos de intertextualidad; microrrelatos que reproducen la trama principal en el interior de la novela; utilización de figuras abstractas, geométricas, aritméticas o gramaticales; cohesión entre el contenido argumental y su distribución formal, pretendiendo una perfecta correlación entre forma y contenido. Se rechaza, ante todo, la metáfora tradicional, ya que ella es considerada como el principal artífice de la visión antropomórfica que reorganiza las relaciones entre el individuo y el mundo mediante los parámetros estéticos o afectivos que recomponen el mundo en un orden esencialmente humano. Robbe-Grillet, al

\footnotetext{
${ }^{10}$ [d] er Leser hat bei den Texten nicht nur ein Wörtchen mitzureden, er trägt vielmehr dazu bei, sie als solche überhaupt erst zu konstituieren, ist er es doch, der sie letzten Endes funktionieren last.

11 'An einer Schöpfung teilhabe, dass er seinerseits das Werk-und die Welt-erfinde' "mündig gewordener Partner des Autors".
} 
igual que más tarde el filósofo francés Michel Foucault en su famoso libro Les mots et les choses (1965) y otros nuevos novelistas, pretenden reemplazar la metáfora intentando restablecer las distancias entre el hombre y las cosas, liberándolas de toda interferencia humanizante.

Para poner en práctica a estos aspectos mencionados, Alain Robbe-Grillet "explota los relatos policiales ampliando y cambiando ciertas posibilidades inherentes en ellos, tal como el modernismo modificó el mito. Para Robbe-Grillet, [...], la nueva novela es un relato detectivesco invertido"13 (Marcus, 2003, p. 250). En la misma línea argumenta Stefano Tani, según el cual Robbe-Grillet sería un autor que considera el género policial como "el medio ideal del posmodernismo en su forma invertida, la novela antidetectivesca, que frustra las expectativas del lector, transforma un género masivo en una sofisticada expresión de una sensibilidad avant-gardista, y sustituye al detective como carácter central y ordenador por la admisión descentralizadora y caótica del misterio sin solución"14 (citado en Marcus, 2003, p. 252).

\section{ANÁLISIS DE LAS GOMAS}

El proceso de rupturas formales e inversión y parodización posmoderna del género policial clásico en la obra literaria de Robbe-Grillet es gradual, pero ya comienza en su primera novela Las gomas cuyo formato policial es aún claramente a la vista. De hecho, casi ganó un premio como mejor novela policial del año 1953 (ver Symons, 1992, p. 222). También Bruce Morrisette (1963) afirma al respecto que "[u]na lectura muy superficial en rigor podría hacer pasar Las gomas por una ingeniosa novela policial con resolución sorpresiva, un poco a la manera de la famosa novela [...] La muerte de Roger Ackroyd, donde el detective-protagonista resulta ser al final de cuentas el verdadero culpable" ${ }^{15}$ (p. 50). También la trama se puede considerar claramente policial. En una ciudad probablemente flándrica que se parece algo a Amsterdam, un hombre que se llama Garinati ha recibido de Bona, que dirige las acciones de una amplia organización política anarquista, el encargo de matar en su propia casa, en un lunes a las siete y media en el tarde, al profesor de economía Daniel Dupont. Debido a que Garinati no obedece estrictamente las órdenes de su

\footnotetext{
13 '...exploits detective stories by expanding and changing certain possibilities in them, just as modernism had modified the potentialities of myth'. For Alain Robbe-Grillet, [...], the nouveau roman is an inverted detective story.

14 ...the ideal médium of postmodernism in its inverted form, the anti-detective novel, which frustrates the expectations of the reader, transform a mass-media genre into a sophisticated expression of avant-garde sensibility, and substitutes for the detective as central and ordering character the decentering and chaotic admission of mystery, of non-solution. También según Julian Symons (1992), "Robbe-Grillet está interesado en la técnica y los detalles de la detectión y no en su desenlace" ("Robbe-Grillet is interested in the technique and minutiae of detection, not its ultimate end") (p. 221).

${ }^{15}$ [u]ne lectura trés superficielle pourrait á la rigueur faire passer les Gommes pour un ingénieux roman policier á dénoueement-surprise, un peu dans le genre du fameux [...] le Meutre de Roger Ackroyd, oú le detective-protagoniste se révéle etre en fin de compte le vrai coupable.
} 
jefe, su bala hiere a la víctima solamente en forma leve en el brazo. Para evitar un segundo atentado, Dupont incita a su médico y amigo Juard, en cuya clínica se esconde hasta el día siguiente, de declarar oficialmente su muerte para engañar así tanto a la organización criminal como a la policía local. Por no confiar en esta última, el Ministerio del Interior envía aun en la noche del lunes al martes al joven inspector Wallas a la ciudad-puerto que recuerda remotamente de su infancia y donde comienza el martes en la temprana mañana con sus investigaciones. La geografía de la ciudad con sus muchos canales, puentes, filas de casas idénticas y calles circulares le hace casi imposible la orientación. Además, su reloj se paró justamente a la hora del intento de asesinato, es decir, a las 19:30 horas; lo que agrega a la desorientación espacial además una temporal. Las huellas que Wallas encuentra son pocas y contradictorias, al igual que los testimonios de las personas que logra interrogar. Tampoco los diálogos con el envidioso comisario Laurent le ayudan mucho. En la tarde del martes, Wallas vuelve a la casa de Dupont porque a base de una misteriosa carta postal, que le es entregada a pesar de que aparentemente él no es al que ha sido dirigida, llega a la convicción de que el asesino se presentará allá por segunda vez, según el sabido hecho que el asesino suele volver al lugar del crimen. En la misma pieza, en la que Garinati intentó el día anterior matar a Dupont, Wallas espera al criminal. En vez de ese aparece el profesor Dupont, que por su apurada huida a la clínica olvidó ayer importantes papeles de su oficina, a la que entra con cuidado y con una pistola en la mano. Ambos tiran al mismo momento, pero Wallas mata a Dupont cuya pistola se tranca. En este mismo instante el reloj de Wallas, que había quedado parado justamente veinticuatro horas antes, sigue andando nuevamente. Al detective Wallas, que se siente fracasado y convertido en "asesino", no se le castiga ni se le investiga, sino, al contrario, su jefe le asigna otro caso.

No cabe duda que a un nivel superficial, en el sentido de E. A. Poe, se trata de una trama policial. Hay un crimen, un asesino, un muerto, policías, un detectiveinspector, una investigación policial y una aparente aclaración del caso al final. Además, hay la típica rivalidad y desconfianza entre la policía y el inspector-detective que es percibido como competencia indeseada, un hecho del que la crítica sencillamente no se ha percatado. Sin embargo, no se trata de una novela policial común. En primer lugar, el detective-inspector Wallas no logra la ejecución de su encargo, es decir, él fracasa en su búsqueda de la verdad, no aclara el caso y toma preso al criminal, sino es él que da el tiro mortal, convirtiéndose así en el supuesto criminal e infringiendo así una regla básica del modelo policial clásico en el sentido de que el detective jamás puede ser al mismo tiempo el culpable. En segundo lugar, la víctima no es asesinada al comienzo de la trama, como suele ser en el esquema policial convencional, sino recién al final, como sucede, por ejemplo, también en Crónica de una muerte anunciada de G. García Márquez. Mientras que en la novela policial tradicional los indicios llevan a la aclaración del crimen, "aquí los indicios malentendidos llevan al verdadero asesinato"16

16 ...hier führen missverstandene Indizien zum tatsächlichen Mord 
(Unmüssig, 1997, p. 56). En tercer lugar, el malhechor, es decir, el detective-inspector Wallas, no es obligado a responder por sus actos y recibe inmediatamente un nuevo encargo. De esta manera se infringe el optimismo burgués del género policial clásico y su confianza en el buen fin de la trama que reestablece el orden y garantiza la victoria del bien, representado por el detective-inspector, sobre el mal, representado por el criminal. Estas tres modificaciones e inversiones indican claramente que Robbe-Grillet intenta aquí más bien "una parodia de la novela detectivesca"17 convencional (Mölk, 1969, p. 43).

Esta afirmación se puede comprobar muy bien mediante el análisis de la figura concreta del detective-inspector Wallas ${ }^{18}$. Comenzando con el último, se trata de "un hombre todavía joven, alto, tranquilo, de facciones regulares" (Las gomas, p. 39), a quien "le gusta andar en el aire frío de este invierno que empieza" (p. 45). Su jefe, Fabius, del Ministerio del Interior, lo ha enviado a esta ciudad para aclarar el caso del asesinato del Profesor Daniel Dupont, ya que se trata, según Fabius, de un caso de destrucción contra "hombres cuyo papel político, aunque no oficial, es sin duda muy importante [...]" (p. 54-55), es decir, de un caso de relevancia pública. Debido a que Wallas trabajaba antes en otro ministerio, no siente por Fabius "la ciega veneración de algunos de sus colegas" (p. 54). Se trata más bien de una persona en la tradición de A. Dupin y Sh. Holmes que no está casada y no tiene hijos, vive marginada de la sociedad, se viste en forma extravagante, tiene algunos "ticks" raros, toma morfina y se destaca del resto por su increíble capacidad intelectual (Mölk, p. 44). Psicológicamente parece más bien inestable porque, por ejemplo, en el camino a la clínica cuando "le conviene ir por la izquierda, porque allí se encuentra la clínica, va por la derecha, [...]" (p. 118). Al final de la novela, Wallas parece como trastornarse y quedar agotado con los nervios (p. 220-221).

$\mathrm{Su}$ método de investigación consiste, por un lado, en los interrogatorios tradicionales que en parte realiza junto con el comisario Laurent, con el que comparte también la capacidad de abducción, es decir, de establecer hipótesis y hacer conjeturas acerca de los más diversos aspectos del caso. Sin embargo, cuando el comisario conjetura que en el caso de Daniel Dupont "puede tratarse de un suicidio" o que "el disparo que mató a Daniel Dupont partió de otro mundo", es decir, se trataría de "un trabajo de especialistas que han dejado visiblemente pocas cosas al azar", Wallas sostiene que estas hipótesis son posibles de comprobar "por la posición de las balas" (p. 61-62). Aquí Wallas, al igual que otro inspector de la policía, manifiesta claramente su inclinación por una investigación que incorpora elementos científicos como, por ejemplo, un "examen de los indicios materiales", de las "huellas digitales", etcétera (p. 171-72). Bastante más adelante, el Servicio Médico Legal confima que "[u]na bala del siete setenta y cinco, disparada de frente, a unos cuatro metros" (p.

\footnotetext{
17 ...eine Parodie des Detektivromans. Linda Unmüssig habla, incluso, de una intención robbe-grilletiana de llevar el género policial 'ad absurdum' (p. 56)

${ }^{18}$ Muchos críticos asocian el apellido Wallas con el autor inglés de novelas policiales Edgar Wallace.
} 
200) mató a Daniel Dupont, descartando de plano la conjetura del comisario arriba mencionada.

Además, Wallas se revela como buen observador. Al final de la primera parte observa que la pistola, con la que se mató a Dupont, es del mismo modelo que la suya y que una bala ha sido ya disparada. Poco más adelante, en el contexto del interrogatorio de la señora Bax, Wallas, al revisar el edificio en el que ella vive, constata que el dispositivo de alarma había sido forzado para impedir el contacto al abrirse la puerta. Esta observación precisa le hace abducir que "este trabajo, ejecutado con el brazo extendido", fue realizado por un hombre con "una fuerza muscular poco común" (p. 100).

Sin embargo, cuando su método más racional y científico no le ofrece ninguna otra pista y no tiene otra cosa que hacer, sigue su corazonada de que el criminal podría presentarse nuevamente en el lugar del crimen y se encuentra con Daniel Dupont, a quien mata por confundirlo con el criminal.

En su búsqueda detectivesca del criminal y personal de una goma ${ }^{19}$ determinada, Wallas camina o más bien vaga por esta ciudad laberíntica con sus calles circulares que lo llevan repetidas veces a los mismos lugares. Entre otros, a una papelería abierta a la que entra "sin propósito determinado", donde una muchacha muy joven, que "[t]iene una cara bonita, un poco malhumorada, y cabellos rubios", le sonríe con "sus ojos, sus labios carnosos, ligeramente entreabiertos" (p. 58), provocando cierta atracción sexual en él. Algo parecido le pasa en la interrogación de la hermosa exesposa de Daniel Dupont, Evelyne, la que Wallas se imagina, en un posterior monólogo interior, en el dormitorio junto con el profesor Daniel Dupont como una "esposa demasiado carnal". También en esta situación, Wallas siente el deber y la necesidad de "aparta[r] esta imagen de su mente" (p. 159). Además, ve una fotografía con un hombre maduro y un niño en traje de Primera Comunión que levanta los ojos hacia una gran señora en un vestido.

$\mathrm{Si}$ agregamos como otro lugar repetido la encrucijada, en la que Wallas varias veces suele mirar por todos lados y esperar a alguien, no sorprende que muchos críticos literarios consideran, a nivel subliminal, que "la aventura de Wallas en Las gomas es una versión moderna de la tragedia de Edipo"20 (Morissette, 1969, p. 53). Según esta lectura alegórica, Daniel Dupont sería Layo, el padre de Wallas (Edipo), el que sentiría "una atracción erótica"21 (Unmüssig, 1997, p. 58) por Evelyne (Yocasta), supuestamente su madre. De hecho, hay un sinnúmero de indicios por una lectura desde una perspectiva edipal que, sin embargo, son casi imposibles de descubrir a la primera lectura. No hay solamente el hecho ya mencionado de la estructura laberíntica de la ciudad por la que Wallas vaga sin orientación, sino que hay nombres de calles ("Rue de

\footnotetext{
${ }^{19}$ Según Ulrich Mölk, a nivel alegórico, detrás de la búsqueda de la goma se esconde la "búsqueda de sí mismo" (Suche nach dem Selbst).

${ }_{20}^{20}$ I']aventure de Wallas dans les Gommes est une versión moderne de la tragédie d'Oedipe.

21 ...eine erotische Anziehung.
} 
Corinthe", "route de Delf", etcétera), paisajes, estatuas de bronce y decorados griegos. A un nivel más profundo, la búsqueda de Wallas del asesino del profesor Dupont parece ser, además, la búsqueda de su padre, que se negó a reconocerlo. Wallas es un hijo ilegítimo, y ahora, en esta ciudad de canales, de puentes colgantes, de plazas y fachadas, revive los recuerdos de una de las más tristes aventuras de su infancia y la memoria de su madre. El policía tarda en comprender -en realidad él nunca lo comprenderá, será el lector el que lo adivine- que en esta ciudad vivía su padre: era el profesor Dupont a quien Wallas ha venido a defender contra los atentados terroristas y a quien por una equivocación mata por su propia mano. Wallas es Edipo: su drama culmina en el momento en que asesina a su padre sin saberlo... (Albérés, 1971, p. 167-68).

A estos datos debe agregarse la figura del borracho que en el Café des Alliés le plantea a Wallas el siguiente acertijo: "¿Cuál es el animal que es parricida por la mañana, incestuoso al mediodía y ciego por la noche?” (Las gomas, p.196). Según Ulrich Mölk (1969), este borracho une en su persona "rasgos de Tiresias, de la

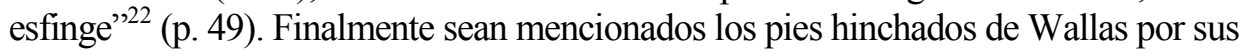
largas caminatas que, obviamente, puede asociarse al significado literal de la palabra griega Edipo (es decir, pie hinchado).

Ahora bien, el hecho que Robbe-Grillet confirma en esta novela la sentencia de Ernst Bloch en el sentido de que la tragedia sofoclea Edipo rey representa la "materia prima de lo detectivesco", no debe hacernos olvidar que Robbe-Grillet le quita a su novela la dimensión trágica y no escribe una tragedia. Wallas, a diferencia de Edipo, no es culpable desde el comienzo y su destino no está sellado de antemano, pues el "crimen" es cometido recién al final de la novela. "Robbe-Grillet mismo denomina a Wallas por eso como 'anti-Edipo' y no como 'nuevo Edipo'. Más preciso aún parece el concepto 'Edipo inverso' de Ricardou, con el que apunta al hecho de que Wallas no revela una verdad dada, sino que crea más bien los hechos",23 (Schaefer, 2013, p. 123). La ya arriba mencionada inversión paródica del esquema policial tradicional es complementada así también por una del género trágico. Al fracaso de la búsqueda de la verdad de Wallas como detective-inspector corresponden, a nivel subliminal, "las siempre estructuralmente ambivalentes referencias a Edipo"24 (p. 125) que no permiten fijar un significado determinado, revelando así claramente rasgos posmodernos.

A nivel formal, la inversión paródica se logra, por ejemplo, por medio de testimonios contradictorios y la confusión de los mismos investigadores en torno al muerto. Tanto por la entrega de sensaciones y angustias en largos monólogos interiores de diferentes personas como mediante la mezcla de escenas imaginarias y reales sin la entrega de ninguna herramienta, que le permita al lector distinguir entre

\footnotetext{
${ }^{22}$ Züge des Tiresias, der Sphinx.

${ }^{23}$ Robbe-Grillet selbst bezeichnet Wallas daher als 'anti-Oedipe', nicht als 'neuen Ödipus'. Noch präziser scheint Ricardous Begriff des 'Oedipe inverse', mit dem er darauf abhebt, dass Wallas keine gegebene Wahrheit enthüllt, sondern die Fakten erst schafft.

24 ...die durchweg ambivalent gestalteten Ödipus-Bezüge. 
ellos, Robbe-Grillet presenta "una realidad imprecisa, nebulosa y brutal, pues nunca acaba de esclarecerse a lo largo de las horas" (Albérés, 1971, p. 168). En vez de un proceso de aclaración había que hablar aquí más bien de un proceso de enigmatización de la realidad.

Especialmente interesante es en este contexto formal también la deconstrucción de los conceptos tradicionales tanto del tiempo y espacio como de la continuidad y causalidad. La crítica literaria se ha concentrado, ante todo, en la ruptura del tiempo cronológico, basándose en la afirmación robbegrilletiana de la tapa del libro, en el sentido de que este libro sería la descripción de aquellas veinticuatro horas que pasarían entre el tiro del asesino y la muerte de la víctima, de aquel tiempo que la bala necesitaría para correr tres o cuatro metros, es decir, de aquellas veinticuatro horas superfluas entre el lunes en la tarde hasta el martes a la misma hora (Mölk, 1969, p. 45). Barthes habla por eso de un tiempo circular y Morissette de una trayectoria circular. Otros críticos literarios como Mölk distinguen en esta novela entre el "tiempo falso" 25 , que serían las veinticuatro horas denominadas superfluas por Robbe-Grillet, que el hombre llena con sus planos infructuosos, confusos, contradictorios y absurdos, y el "tiempo auténtico. Él es medida pura y movimiento puro, el tiempo físico o neutral, el tiempo en el cual el hombre no tiene influencia"26 (Mölk, 1969, p. 46). Lo relevante es que Robbe-Grillet muestra en esta novela que es posible concebir el tiempo no solamente en forma linear, comprobando así "que el tiempo es un constructo y no una entidad independiente del observador" $^{27}$ (Schaefer, 2013, p. 135).

Respecto de la deconstrucción del espacio, R. Barthes habla ya en 1954 de la disolución del espacio euclidiano tradicional y muestra por medio de la mirada y perspectiva de Bona que tanto el espacio euclidiano como el no euclidiano aparecen como producto puro de la percepción humana (p. 137).

De esta forma, Robbe-Grillet, al hacer fracasar al detective-inspector Wallas (alias Edipo) en su búsqueda de la verdad y de la propia identidad, crea en Las gomas una novela híbrida, "metaficcional, reflexiva y paródica"28 (Stolzfus, 1964, p. 12), que mezcla varios elementos policiales clásicos (método de investigación, rivalidad entre policía y detective, investigación racional, etc.) y algunos pocos elementos negros (atracción sexual, crítica social ) y, ante todo, parodia tanto el género policial como la tragedia griega que le sirve de intertexto. Además, a nivel literario formal, rompe, ante todo, con los conceptos convencionales del tiempo y espacio creando así un texto literario que expresa a nivel formal la adherencia de Robbe-Grillet al principio de la incertidumbre.

\footnotetext{
25 ...falsche Zeit.

26 ...echte Zeit. Sie ist reines Mass und reine Bewegung, sie ist die physikalische oder neutrale Zeit, die Zeit, die das Bewusstsein des Menschen nicht trübt.

27 ...dass die Zeit ein Konstrukt und keine beobachterunabhängige Entität ist.

28 ...metafictional, reflexive and parodic.
} 


\section{ANÁLISIS DE EL MIRÓN}

Mientras que en Las gomas hay todavía una anécdota recuperable, la historia "comienza a aproximarse al grado cero en Le Voyeur, donde los objetos cobran una inusitada relevancia en detrimento de la anécdota y de los personajes. Serán los objetos descritos los que condicionan al lector a intuir la existencia de un argumento" (Martínez, 1987, p. 40-41). Este consiste, resumidamente, en un viaje de un vendedor ambulante de relojes, Mathias, a una isla pequeña, en la que nació y creció. Originalmente pensaba quedarse solamente un día en la isla, pero como pierde la ferry de la tarde está obligado a permanecer tres días más en ella. Al llegar a la isla, observa diferentes signos geométricos como, por ejemplo, "un fino bramante de cáñamo, en perfecto estado, cuidadosamente arrollado en forma de ocho" (Robbe- Grillet, 1969, p. 8), "dos pequeños círculos" (p. 14) o "un triángulo" (p. 15). Estas figuras geométricas permanentemente repetidas adquieren posteriormente una significación central pues durante el primer día de su estadía total de cuatro días acontece la muerte accidental o el crimen sexual de una niña de trece años, Jacqueline, que fue amarrada con un bramante de cáñamo y tirada al mar. Hay indicios de que el protagonista Mathias podría ser el criminal, sin embargo, él mismo parece no acordarse. En las tres partes de parecido largo, hay varios saltos en el tiempo y se mezclan “imágenes retropectivas e intercaladas [...], escenas 'falsas', imaginadas o ideadas como coartadas" (Martínez, 1987, p. 45), de tal forma que el lector no percibe claramente si se describe una situación del presente o del pasado y no queda claro "si el crimen se cometió efectivamente o nace solamente de la fantasía del protagonista. Nadie lo declara culpable y también se desconoce su motivo para el acto posible"29 (Ziehm, 2012, p. 5). Así Mathias ni es acusado ni tomado preso y no se aclara para nada la muerte de Jacqueline. Al final, la figura central vuelve con el ferry a tierra firme.

De esta forma, respecto de la trama policial, tenemos que concluir que estamos ante una novela antidetectivesca. La trama ofrece, efectivamente, ciertas similitudes con el género policial, pero no así su tratamiento narrativo. Robbe-Grillet nos relata aquellos hechos que no tendrían ninguna pertinencia narrativa en una novela policial convencional y omite justamente aquellos que sí la tendrían. Es muy significativo que el crimen, punto de partida en la trama policial tradicional, ni siquiera sea mencionado. Tampoco hay un detective, por lo menos no uno convencional. En cierta medida se puede considerar al protagonista Mathias un detective en el sentido de que actúa como tal al borrar huellas y juntar indicios, lo que suelen hacer justamente los detectives tradicionales (Ziehm, 2012, p. 11). Y al final de la novela, el supuestamente cupable Mathias queda impune. Aquí hay, por tanto, una clara inversión de la trama policial clásica. Solo quedan como elementos policiales tradicionales: un probable crimen, algunos indicios y pistas, un probable testigo ocular (=Julien), algunos sospechosos (Pierre, Julien y Mathias), la isla como un lugar aislado como lo 29 ...ob das Verbrechen tatsächlich geschehen ist oder der Phantasie des Protagonisten entspringt. Niemand
überführt ihn eindeutig und auch sein Motiv für die mögliche Tat bleibt unbekannt. 
tenemos, por ejemplo, en el relato clásico de A. Christie, Diez negritos, y, finalmente, una inspección del cadáver, la que, sin embargo, no revela las circunstancias exactas del crimen ni da suficientes pruebas para un asesinato (p. 12).

Desde el punto de vista formal, había que destacar, ante todo, el desorden cronológico que le hace al lector casi imposible la restitución de sentido de esta obra literaria. El tiempo se organiza aquí, según Martínez, "como repetición o desfase entre los diferentes planos temporales: repetición de imágenes obsesivas, recuerdos o anticipaciones; desfase entre los diferentes planos, que se suceden sin transición entre ellos" (45). Muy pocos lectores se percatan que todo este texto se construye sobre un desfase temporal: el episodio central, e. d. el momento de la supuesta violación y del asesinato de la muchacha Violette (=Jacqueline), es un gran espacio en blanco, un salto en el tiempo del anónimo protagonista Mathias. Al final del capítulo I, lo habíamos dejado pedaleando hacia el acantilado y lo volvemos a encontrar, en el capítulo II, una hora más tarde, parado en el cruce de los caminos. A partir de este momento, todas las preocupaciones de Mathias, un joven vendedor de relojes de pulsera que recorre en bicicleta las pocas casas de una isla, se cifran en recuperar ese vacío cronológico, intentando hacer coincidir la cronología de los acontecimientos reales con la cronología de los acontecimientos inventados por él para fundamentar su coartada (Martínez, 1987, p. 45).

Mathias inventa dos coartadas: la visita a la granja de los Marek y la avería de la bicicleta. Ambas acciones imaginarias no son, sin embargo, sino la anticipación de acciones reales que tendrán lugar más adelante. En efecto, Mathias visitará a los Marek en el capítulo III, y la avería de la bicicleta, al final del capítulo II, le ocasiona un leve retraso que le hace perder el barco. Al mismo tiempo, estas dos acciones anticipadas o retrasadas -según se mire- también son repetidas: tendremos la visita imaginaria a la granja y la visita real, la avería imaginaria y la avería real (p. 46).

Esta coordenada cronológica que se caracteriza por los principios formales de la reiteración y el desfase, nos remite al trayecto en forma de ocho que el viajero efectúa por la topografía de la isla y resumen la peripecia vital de Mathias como un incesante ir y venir, un deambular gratuito y reiterativo por un circuito cronológico y espacial perfectamente delimitado y cerrado en la pequeña isla cuya topografía nos es minuciosamente descrita. Y sin embargo, los personajes se pierden como simples peones atrapados en un círculo fatalmente delimitado.

$\mathrm{Si}$ analizamos el circuito que realmente efectúa el protagonista nos encontramos con dos grandes círculos cotangentes en un punto común: el lugar donde se produce el crimen. En efecto, al final del primer capítulo, Mathias se dirige hacia la hondonada del acantilado donde la joven Jacqueline (=Violette) cuida su rebaño, y en los capítulos siguientes regresa al mismo lugar con el fin de hacer desaparecer posibles indicios de su anterior presencia en el lugar del crimen. Por otra parte, lo que estructuralmente se configura como el punto de engarce entre los dos circuitos 
espaciales, está situado en el cruce de los dos caminos, e.d. el que conduce al gran faro y el que llega hasta el pequeño pueblo de Roches Noires (Martínez, 1987, p. 50).

El espacio se dibuja, pues, siguiendo a Patricia Martínez, como dos grandes círculos tangentes, es decir, como un gran ocho recostado que recorre a lo ancho y a lo largo la topografía de la pequeña isla (ver las respectivas palabras de Mathias al tabernero). El primer circuito (desde el muelle hasta el cruce de los caminos) se disgrega a su vez en dos microcircuitos: el primero lo realiza Mathias a pie por el pueblo, mientras el mecánico le arregla la bicicleta; y el segundo, ya en bicicleta, se cierra con la bajada hacia la costa al final del capítulo I. El segundo circuito (desde el cruce de los caminos hasta el muelle), se compone, igualmente, de otros dos microcircuitos: la primera gira de ventas realizada con el fin de elaborar una coartada (capítulo II), y el regreso al acantilado para hacer desaparecer los rastros delatores (capítulo III).

En el punto de intersección de ambos subcírculos, hallamos dos elementos de gran valor simbólico: la estatua de la mujer ataviada con el traje regional que mira hacia el mar y el cartel de cine con el título de la película Monsieur X en el doble circuito. La estatua parece ser un monumento a los muertos. Curiosamente la violada y asesinada muchacha Jacqueline/Violette llevó este traje regional en un foro y en el momento del crimen. Además comparte con la estatua la misma mirada que se pierde en la lejanía. Resulta, por tanto, indudable la relación simbólica entre Violette y la estatua. Lo mismo vale para el cartel del cine.

De esta forma, estamos, según Patricia Martínez (1987), también en el nivel espacial ante "una configuración geométrica perfectamente delimitada, que puede resumirse en dos principios formales: reiteración y desfase: reiteración del trayecto en forma de ocho, repetición de los itinerarios, impecable continuidad de los dos círculos" (p. 53).

Sin embargo, no solo el tiempo y el espacio encuentran su expresión simbólica en la figura geométrica del ocho, sino también el tema de la novela. La figura del ocho parece omnipresente en esta novela. El ocho horizontal aparece en las argollas del puerto, en la madeja de cuerda, en las vetas de madera, en el vuelo de las gaviotas, en el dibujo del humo, en la cadena de la bicicleta, etcétera.

Todos estos objetos analógicos que nos remiten al signo ocho son elementos estructurales dentro del relato, y operan en el nivel textual relacionando los diferentes núcleos temáticos. Por ejemplo, en el centro de un ocho que han marcado unas viejas argollas de hierro sobre la piedra, Mathias "veía una excrecencia rojiza" (Robbe-Grillet, 1969 , p. 15) de un resto de herrumbre oxidada, que fácilmente se puede relacionar con el rojo como símbolo del erotismo y de la violencia, si uno recuerda que el crimen y la violación tuvieron lugar en el punto donde los dos círculos se tocan, y si uno relaciona, a nivel subliminal, el ocho con los ojos (del voyeur Mathias) y los ovarios (de la víctima Violette) (p. 62-64).

Tanto mediante el título francés de la novela Le voyeur, que provoca conscientemente la asociación con el fenómeno erótico del voyeurismo como por la profesión de Mathias, el vender relojes de pulsera, que en inglés se llaman watches, 
palabra que tiene su origen en el verbo to watch' e.d. mirar en castellano, Robbe-Grillet crea una cadena de asociaciones en torno a la figura geométrica del ocho que une todo lo que sucede con la temática central de la violación y del crimen. Con Patricia Martínez (1987) se puede decir que "[e]l signo ocho es metáfora estructural implícita [e.d. no referencial a lo extraliterario; C.F.] del asesinato de la muchacha" (p. 62).

La bicicleta se convierte en este contexto en un símbolo de suma importancia porque no solo sus dos ruedas representan geométricamente el ocho, sino también el triángulo que conforma la otra figura geométrica más recurrente de la novela, e.d. la segunda cadena de objetos analógicos: los objetos punzantes y las geometrías triangulares (ver por ejemplo el puerto triangular, los cuchillos expuestos en el escaparate de la ferretería, la plaza del pueblo, las uñas de los cangrejos, las uñas del propio Mathias, la marca en forma de i griega sobre la piel de Violette, etc.).

Robbe-Grillet relaciona, según Patricia Martínez, también esta segunda cadena de asociación con la temática central: la primera letra de las palabras voyeur y Violette es una $\mathrm{v}$, geométricamente igual a un triángulo. Además, las primeras cuatro letras del nombre Viol-ette coinciden con aquellas de la palabra viol-encia. Ahora, así como arriba el ocho provocó la asociación erótica con los ojos y los ovarios, el triángulo provoca la asociación con el pubis femenino.

De esta forma, las dos metáforas estructurales de la novela terminan, según Patricia Martínez (1987), fusionándose: el doble circuito y las geometrías triangulares, las coordenadas espacio-temporales del crimen y el cuerpo de la víctima que es encontrado con los brazos unidos abajo y las piernas estiradas, es decir, formando dos triángulos (p. 63).

Resumiendo tenemos que concluir que en $E l$ mirón estamos ante una novela antidetectivesca que a pesar de contener algunos elementos del género policial clásico, que ya se mencionó más arriba, y del negro (por ejemplo la violencia y el crimen sexual), invierte aún más radicalmente que en Las gomas las convenciones tanto de la trama policial -omitiendo el momento del crimen, haciendo fracasar la búsqueda policial del supuesto detective y criminal Mathias, que compruebe el hecho de que "el protagonista de Robbe-Grillet se desmaterializa gradualmente" ${ }^{\text {"30 }}$ (Alter, 1966, p. 107)como del aspecto formal, ante todo, por medio de las rupturas radicales del tiempo y del espacio convencionales y el uso de descripciones minuciosas de objetos, que provocan la desorientación casí total del lector en la difícil lectura de esta novela posmoderna y convierten las antinovelas robbegrilletianas en la "sucesión verdadera de la 'corriente subterránea de sentido' de Poe"31 (Kesting, 1976, p. 288).

Pontificia Universidad Católica de Chile* Luis Thayer Ojeda 1303, Depto. 302, Providencia, Santiago (Chile) cfranken@uc.cl

\footnotetext{
${ }^{30}$ le protagoniste de Robbe-Grillet se dématerialisé graduellement.

31 eigentliche Nachfolge von Poes 'under-current of meaning'.
} 
Este artículo es resultado del Proyecto Fondecyt Regular No 1130218 "Narrativa policial universal clásica, negra y posmoderna".

\section{OBRAS CITADAS}

Albérés, R. M. (1966). Metamorfosis de la novela. Madrid: Taurus, 1971.

Alter, Jean. (1966) La visión du monde d'Alain Robbe-Grillet. Structures et significations. Genéve: Librairie Droz.

Butters, Gerhard. (1977). "Roman und Konstruktion-Zur Poetik des Nouveau Roman". Zeitschrift für französische Sprache und Literatur. Cuarderno adicional: Número 4: Aufsätze zur Literaturwissenschaft (1). № 163, 71-89.

Cawelti, John G. Adventure, Mystery, and Romance. Formula Stories as Art and Popular Culture. Chicago y Londres: The University of Chicago Press, 1976.

Guerrero, Pedro Pablo. (1996). “Así fue el 'Nouveau Roman””. El Mercurio. Suplemento Revista del Libro, N 361 (7 de abril), 1, 4-5.

Janvier, Ludovic. (1967). Literatur als Herausforderung. Die neue Welt des Nouveau Roman. Munich: C. H. Beck.

Kesting, Marianne. (1976). "Reseña" del libro: Formen und Ideologien des Kriminalromans de Ulrich Schulz-Buschhaus. Romanische Forschungen, Vol. 88, 2/3, 284-288.

Lange, Wolf-Dietrich (1971) (ed.). Französische Literatur der Gegenwart. In Einzeldarstellungen. Stuttgart: Alfred Kröner.

Marcus, Laura. (2003). "Detection and literary fiction". Martin Priestman (ed.). The Cambridge Companion to Crime Fiction. Cambridge (GB): Cambridge University Press, 245-67.

Martínez, Patricia. (1987) "Introducción” a Alain Robbe-Grillet, El mirón. Editado y traducido por Patricia Martínez. Madrid: Cátedra, 7-70.

Mölk, Ulrich. (1969). "Vom Detyektivroman zum Nouveau roman. Versuch über Alain Robbe-Grillets 'Les Gommes'.’ En: Giessener Universitätsblätter, Vol. I, 1, 40-51.

Morrissette, Bruce. (1963). Les romans de Robbe-Grillet. Paris: Les Éditions de Minuit.

Porter, Dennis. (1981). Pursuit of Crime. Art and Ideology in Detective Fiction. New Haven y Londres: Yale University Press.

Robbe-Grillet, Alain. (2001). Las gomas. Trad. Jordi Petit Fontseré. 2da ed., Barcelona: Anagrama.

_ (1969). El mirón. Trad. Juan Petit. Barcelona: Seix Barral.

— (1964). Por una nueva novela. Trad. Juan Petit. Barcelona: Seix Barral.

Sábato, Ernesto. (1972). Tres aproximaciones a la literatura de nuestro tiempo. RobbeGrillet, Borges, Sartre. 2da ed., Santiago de Chile: Ed. Universitaria.

Schaefer, Christina. (2013). Konstruktivismus und Roman. Erkenntnistheoretische Aspekte in Alain Robe-Grillets Theorie und Praxis des Erzählens. Stuttgart: Franz Steiner Verlag. 
Stolzfus, Ben F. (1964). Alain Robbe-Grillet and the French Novel. Carbondale: Southern Illinois University ÑPress.

Symons, Julian. (1992). Bloody murder. From the Detective Story to the Crime Novel. $3^{\mathrm{a}}$ ed. revisada. Nueva York: The Mysterious Press.

Unmüssig, Linda. (1997). Alain Robbe-Grillets Position im literarischem Feld. Versuch einer Anwendung von Pierre Bourdieus Theorie der Praxis auf Nouveau Roman und Nouvelle Autobiographie. Hamburgo: Diolomarbeiten Agentur.

Wilhelm, Kurt. (1969). Der Nouveau Roman. Ein Experiment der französischen Gegenwartsliteratur. Berlín: Erich Schmidt Verlag.

Ziehm, Alida. (2012). Alain Robbe-Grillets 'Le Voyeur'. Ein Kriminalroman. Norderstedt: GRIN Verlag. 